\title{
Turistas de São Raimundo Nonato - PI: perfil e grau de satisfação quanto aos serviços de alimentação
}

\author{
Tourists of São Raimundo Nonato - PI: profile and satisfaction with food services
}

\section{Los Turistas de São Raimundo Nonato - PI: perfil y satisfacción con los servicios de alimentos}

\author{
Eveline Porto Sales Aguiar ${ }^{1}$ \\ Stella Maria Sousa Carvalho ${ }^{2}$
}

\begin{abstract}
Resumo
Sabendo-se que São Raimundo Nonato, é um dos destinos turísticos do Estado do Piauí, levantou-se a necessidade de conhecer o que o turista espera encontrar nos serviços de alimentação do município. Assim, este trabalho tem como objetivo principal caracterizar o perfil do turista que visita a cidade e traçar seu grau de satisfação quanto aos serviços de alimentação do município. Desta forma, foi utilizada uma amostra de 97 turistas que estiveram na cidade, com diferentes propósitos de viagem em quatro diferentes meios de hospedagem. Foram realizados questionamentos, inicialmente, sobre o perfil do turista, seguido do levantamento da percepção deste quanto à oferta alimentar local, focando principalmente nos atributos de escolha de um serviço de alimentação, assim como também, uma avaliação sobre: sabor, capacidade de despertar o apetite, apresentação do prato, higiene e preço. A análise estatística do estudo apontou que fatores como higiene e limpeza, um bom atendimento (18\%) e qualidade dos alimentos (17\%) interferem de forma significativa na escolha de um serviço de alimentação. Todavia, os turistas apontaram itens como: cardápio, decoração e equipamentos de lazer como elementos que poderiam ser diferenciais nos estabelecimentos de alimentação. Os resultados apontaram um nível satisfatório na qualidade dos serviços e produtos ofertados. Em consequência, os serviços de alimentação foram considerados aceitáveis, confiáveis e que atendem às necessidades dos clientes. Foram apontadas recomendações em âmbito turístico e alimentício, para contribuir para o desenvolvimento turístico da cidade, podendo ser reconhecida como um polo de referência.
\end{abstract}

Palavras-chave: perfil dos turistas; serviços de alimentação; satisfação.

\footnotetext{
${ }^{1}$ Professora dos Cursos de Eventos e Guia de Turismo do Instituto Federal do Ceará - IFCE. E-mail: evelineps@gmail.com.

${ }^{2}$ Coordenadora do Eixo Hospitalidade, Lazer e Turismo do Instituto Federal do Piauí - IFPI; Professora do Curso de Guia de Turismo do Campus São Raimundo Nonato do IFPI. E-mail: stella@ifpi.edu.br.
} 


\begin{abstract}
Knowingthat SanRaimundoNonato, is one of tourist destinations in thestate of Piaui, arose the need to knowwhat the touristexpects to findin thefood servicesof the municipality.Thus, this study's main objective is to characterize the profileof touristsvisiting the cityand drawtheir degree ofsatisfaction withfood servicestothe municipality.Thus, we used asample of 97tourists whowere in town, with differentpurposesof travel byfourdifferentmeans of accommodation. Questionswere conductedinitiallyon the profile oftourists, followed by thesurveyon theperceptionoflocal foodsupply, mainly focusingon the attributes ofachoice offood service, as well asan evaluation of: taste,theability to arouseappetite,presentation of the dish, hygiene and price.Statistical analysis of thestudy indicatedthat factors such ashygiene and cleanliness,good service(18\%) and food quality(17\%) had a significant impacton the choice ofafood service.However, tourists pointeditems such asmenu,decor andleisure facilitiesas elements thatcould bedifferencesineating establishments. The results showedasatisfactory levelofqualityservicesand products offered.As a result, food serviceswere acceptable, reliable andmeet the needs ofcustomers.Recommendationswereaimedatthe touristand food, to contribute tothe developmentof tourism in thecity and can berecognized asapole ofreference.
\end{abstract}

Keywords: profile of tourists; food services; satisfaction.

\title{
Resumen
}

Sabiendo que San Raimundo Nonato, es unode los destinos turísticos en el estadode Piauí, surgióla necesidad de conocerlo que el turistaespera encontrar enlos servicios de alimentacióndel municipio.Por lo tanto, el objetivo principal de este estudioes caracterizarel perfil delos turistas que visitanla ciudady sacarsu grado desatisfacción con los serviciosde alimentos parael municipio. Por lo tanto, se utilizó una muestrade 97turistas queestaban en la ciudad, condiferentes propósitosde los viajesde cuatro manerasdiferentesde alojamiento. Las preguntasse llevaron a caboinicialmente enel perfilde los turistas, seguido de laencuesta sobre la percepciónde la ofertalocal de alimentos, centrándose principalmente en los atributos deuna selección deservicios de alimentos, así como una evaluación de: el gusto, la capacidad dedespertarapetito,presentación del plato, la higiene y el precio. El análisis estadísticodel estudio indicaronque factores como lahigiene y limpieza,buen servicio(18\%)y lacalidad de los alimentos(17\%) tuvieron un impacto significativo enla elección de unservicio de comida.Sin embargo, los turistas señalaronelementos tales comoinstalaciones demenú, la decoración y el ocio comoelementos que podrían serlas diferencias enlos establecimientos de alimentación. Los resultados mostraronun nivel satisfactorio decalidad de los serviciosy productos ofrecidos. Como resultado, los servicios de comidaera aceptable, fiable y satisfacer las necesidades delos clientes. Las recomendaciones fuerondirigidas alos turistasy los alimentos,para contribuir aldesarrollo del turismo enla ciudad ypuede ser reconocido comoun polo dereferencia.

Palabras llave: perfil de los turistas; servicios de alimentos; satisfacción. 


\section{Introdução}

O turismo é uma atividade que movimenta a economia de um país, Estado ou região responsável muitas vezes pelo efeito propulsor de geração de emprego e renda bem como pela entrada de divisas que permite equilibrar a balança comerciale ainda impulsionar a atividade empresarial.

O turista ao visitar uma determinada localidade está disposto a gastar parte da sua renda no local de destino. Os estudos feitos pela Organização Mundial do Turismo (OMT, 2001, p.10), mostram que:

[...]os gastos dos turistas não somente se limitam ao pagamento do aluguel de um quarto no hotel, mas também destinam parte da renda disponível a uma grande variedade de bens de consumo como alimentos, transportes, entretenimentos, excursões, atividades diversas e etc.

Para efeitos de esclarecimentos, deve-se entender turista como sendo um visitante que permanece no local visitado num período superior a 24 horas, ou pernoite.

Conforme o Programa de Regionalização do Turismo do Ministério do Turismo (MTur), os destinos indutores do desenvolvimento turístico regional são aqueles que possuem infraestrutura básica e turística e atrativos capazes de atrair o turista, que se caracterizem como núcleo receptor e/ou distribuidor de fluxos turísticos, ou seja, são aqueles capazes de atrair e/ou distribuir significativo número de turistas para seu entorno e dinamizar a economia do território em que estão inseridos (MTUR, 2007). O município de São Raimundo Nonato (SRN) foi escolhido como um dos 65 destinos indutores do turismo do Brasil, sendo um dos destinos do Estado do Piauí. SRN é um destino que atrai turistas de vários estados do Brasil, motivados principalmente em conhecer o Parque Nacional Serra da Capivara (PNSC) e o Museu do Homem Americano. Deste modo, se faz necessário caracterizar o turista de SRN, no intuito de identificar a realidade da demanda turística e as condições socioeconômicas destes.

Assim, a pergunta que norteia este estudo é: "O serviço de alimentação oferecido pelo município satisfaz o turista?". Partindo desta problemática, a hipótese de trabalho assenta-se na constatação do grau de satisfação do turista quanto aos serviços de alimentação, pois 
como citado anteriormente o gasto do turista se destina também ao consumo de alimentos, que serve para o suprimento de suas necessidades fisiológicas, bem como ser fonte de entretenimento e atrativo turístico.

Para a verificação da hipótese enunciada objetivou-se pesquisar a demanda turística real de SRN, ou seja, as pessoas que viajaram efetivamente com fins turísticos abordando-se aspectos como sabor e qualidade dos alimentos servidos, qualidade no atendimento, preço e infraestrutura dos equipamentos de apoio.

Para consecução do objetivo estabelecido, analisaram-se os serviços de alimentação, comportamento de compra do consumidor, turismo e demanda turística. Caracterizou-se a área de estudo, ou seja, o município de São Raimundo Nonato, a fim de identificar a realidade do fluxo turístico e a avaliação da percepção da oferta alimentar.

\section{O Município de São Raimundo Nonato - PI: caracterização geral}

São Raimundo Nonato foi criado pela Lei $n^{\circ} 669$ de 25/06/1912, desmembrado dos municípios de Jaicós e Jerumenha, localizado no sudeste do Piauí, compreende uma área de $2.415,59 \mathrm{~km}^{2}$, com uma população 32.347 habitantes e densidade demográfica de 11,94 hab./km² e bioma característico representado pela caatinga (IBGE, 2010).

Limita-se, ao norte com os municípios de Brejo do Piauí e João Costa, ao sul com Fartura do Piauí, Dirceu Arcoverde e Várzea Branca, a leste com Coronel José Dias e São Lourenço do Piauí e, a oeste com São Braz do Piauí e Bonfim do Piauí. A sede municipal tem as coordenadas geográficas de $09^{\circ} 00^{\prime} 55$ de latitude sul e $42^{\circ} 41^{\prime} 58^{\prime}$ ' de longitude oeste de Greenwich e dista cerca de $530 \mathrm{~km}$ de Teresina, capital do Estado. As principais vias de acesso terrestre são as rodovias: PI-141 e PI-144, BR-020, BR-343 e BR-316 e aeroviário, possui um campo de pouso com $1.200 \mathrm{~m}$ de cumprimento, habilitado para receber pequenos aviões. Ressalta-se que um aeroporto internacional encontra-se em fase de construção (OLIVEIRA FILHO, 2007).

Estado do Piauí está dividido em sete polos de atratividade turística (ESTADO DO PIAUÍ, 2009 apud CARVALHO, 2010, p. 47):Polo Costa do Delta (Delta do Rio Parnaíba), Polo Aventura e Mistério (Parque Nacional Sete Cidades), Polo das Águas (Cachoeira do Urubu), 
Polo Teresina (cidade de Teresina), Polo Histórico Cultural (Cidade de Oeiras), Polo das Origens (Parque Nacional Serra da Capivara) e Polo das Nascentes (Parque Nacional das Nascentes).

São Raimundo Nonato possui como atrativo turístico principal o Parque Nacional Serra da Capivara (PNSC) criado em 05 de junho de 1979, através do decreto federal83.548. Conforme Araújo (2006),o PNSClocalizava-se inicialmente nos municípios de Canto do Buriti, São João do Piauí e São Raimundo Nonato. A partir da década de 1990, com a emancipação política de vários municípios no Estado, a conformação territorial centrou-se nos municípios de Brejo do Piauí, Coronel José Dias, João Costa e São Raimundo Nonato.

O clima que impera na região do Parque Nacional se caracteriza por uma temperatura média anual elevada $\left(28^{\circ} \mathrm{C}\right)$, sendo o mês de junho o mais frio, com temperatura média de $25^{\circ} \mathrm{C}$, máxima de $35^{\circ} \mathrm{C}$ e mínima de $12^{\circ} \mathrm{C}$. Na região do Parque Nacional, estão cadastrados 1223 sítios com arte rupestre, sendo 922 sítios com pinturas, 218 com pinturas e gravuras e 83 somente com gravuras. Dentro dos limites do Parque, são 680 sítios, dos quais 600 são de pinturas e/ou gravuras rupestres. Sessenta e três sítios são aldeias, oficinas líticas e alguns são já do período histórico. Estes números não são definitivos, pois continuamente são descobertos novos sítios no Parque Nacional e seu entorno (FUNDHAM, 2010).

Outro atrativo turístico do município é o Museu do Homem Americano de responsabilidade da Fundação Museu do Homem Americano (FUMDHAM), que foi construído em 1986, com a ajuda do governo francês, onde estão expostos fósseis, cerâmicas e a história do homem americano. Conta com adequada estrutura para receber turistas e pesquisadores e oferece acessibilidade para deficientes físicos ou com mobilidade reduzida.

A cidade conta, ainda, com um monumento de uma cruz de 8 metros de altura, denominado Cruzeiro, localizado no alto da cidade que além de permitir uma vista panorâmica da região é usado para romarias e promessas.

Quantos aos serviços de alimentação SRN possui poucas opções. Os serviços se resumem a alguns restaurantes self service e à la carte; bares; lanchonetes; pizzarias e padarias. No entanto, estes locais oferecem gastronomia típica do Piaú, como a carne de carneiro e de bode, capote, beiju, macaxeira frita e cozida e, doces de buriti, bacuri, manga e limão (BARROS, 2009), além de entretenimento para a população nativa e visitante. A maior 
parte destes serviços concentra-se no centro da cidade. Vale ressaltar a realização desde 2009 de uma mostra gastronômica com concurso gastronômico para a escolha do melhor prato apresentado no evento (PORTAL SRN, 2010). Na Tabela 01, pode-se observar a relação de equipamentos de alimentação, distribuídos em categorias que os representam.

Tabela 01 - Equipamentos de Alimentação do município de São Raimundo Nonato - PI

\begin{tabular}{l|l}
\multicolumn{1}{c|}{$\begin{array}{c}\text { Nome do Estabelecimento de } \\
\text { Alimentação }\end{array}$} & \multicolumn{1}{c}{ Categoria } \\
\hline Bode Assado Luis Tanga & Churrascaria e Restaurante \\
\hline Churrascaria do Ary & Churrascaria e Restaurante \\
\hline Churrascaria Donizete Grill & Churrascaria e Restaurante \\
\hline Churrascaria Siqueirão Grill & Churrascaria e Restaurante \\
\hline Churrascaria Alpendre & Churrascaria e Restaurante \\
\hline Churrascaria Rodeio & Churrascaria e Restaurante \\
\hline Churrascaria Canoa & Churrascaria e Restaurante \\
\hline Churrascaria Izabar & Churrascaria e Restaurante \\
\hline Churrascaria Varanda Grill & Churrascaria e Restaurante \\
\hline Churrascaria O Tijolinho & Churrascaria e Restaurante \\
\hline Caldeirão do Chapolim & Churrascaria e Restaurante \\
\hline Mãe Sinhá (self service) & Churrascaria e Restaurante \\
\hline Restaurante Caminho de Casa & Churrascaria e Restaurante \\
\hline Restaurante Sabor da Terra & Churrascaria e Restaurante \\
\hline Restaurante e Confeitaria Sabor e Arte & Churrascaria e Restaurante \\
\hline Pizzaria Zé Trovão & Pizzaria \\
\hline Paulinho Pizzaria & Pizzaria \\
\hline Pizzaria Ruffo's & Pizzaria \\
\hline Pizzaria R Casarão & Pizzaria \\
\hline Pizzaria La Cinta & Pizzaria \\
\hline Panificadora Saraiva & Padaria \\
\hline Panificadora Pan Mil & Padaria \\
\hline Padaria R Costa & Padaria \\
\hline Panificadora Paladar & Padaria \\
\hline Panificadora Renascer & Padaria \\
\hline Manga Rosa Bar & Bar \\
\hline Altitude Point & Bar \\
\hline O Abrigo & Bar \\
\hline Choppetisco (Bar e Lanchonete) & Bar \\
\hline Romério's Bar & Bar \\
\hline Palafitas Bar & Bar \\
\hline Restaurante Sabor da Terra & Self Service \\
\hline Hotel Bela Vista - Melhor Hotel da cidade & Self Service \\
\hline & \\
\hline
\end{tabular}




\begin{tabular}{l|l}
\hline Restaurante Sabor da Terra & Self Service \\
\hline Real Sabor & Self Service \\
\hline Pousada Zabelê & Self Service \\
\hline Lanchonete Mãe Sinhá & Lanchonete \\
\hline Lanchonete O Netão & Lanchonete \\
\hline Lanchonete O Neto & Lanchonete \\
\hline Lanchonete Mano & Lanchonete \\
\hline Tabôa Lanches & Lanchonete \\
\hline Lanchonete do Frank & Lanchonete \\
\hline Lanchonete e Sorveteria Dandan & Lanchonete \\
\hline
\end{tabular}

Fonte: Portal da Prefeitura Municipal de São Raimundo Nonato - PI.

Conforme a classificação de restaurantes citado por Castelli (2006), os restaurantes de SRN classificam-se do tipo comerciais, caracterizados por possuir instalações simples e cardápios de pratos rápidos e baratos e clientela oriunda de comércio e acomodações próximas. Apesar de SRN ser uma cidade que tem forte apelo para a decoração típica, não se observa restaurantes decorados com artigos típicos da região. Ainda na classificação de Castelli, verificam-se também restaurantes de hotel, os quais servem hóspedes e clientela externa.

Deste modo, acentua-se que a gastronomia de SRN seria relevante para a atração do turista e representaria um importante elemento para o desenvolvimento local da cidade. Para tanto, é preciso que os estabelecimentos alimentícios sejammais bem estruturados, visto que, os serviços de alimentação representam também uma opção de lazer da cidade.

\section{Metodologia}

Trata-se de um estudo descritivo e transversal, com abordagem no grau de satisfação dos turistas que visitaram São Raimundo Nonato - PI, quanto aos serviços de alimentação. Foi adotada nesse estudo uma combinação dos enfoques quantitativos e qualitativos. O estudo foi desenvolvido no período de novembro a dezembro de 2010 nos estabelecimentos de hospedagens localizados em São Raimundo Nonato - PI. O método de amostragem foi do tipo não probabilístico por quotas ou proporcional, em que, segundo Braga (2007, p. 58) "o pesquisador estipula um grupo que tenha similaridade com a população, podendo até se 
apoiar no artifício de segmentação". Foram escolhidos quatro meios de hospedagens para compor a amostra por serem estabelecimentos que concentram maior fluxo de turistas e possuírem melhor estrutura física, além de serem divulgados na mídia eletrônica: Hotel Real, Hotel Serra da Capivara, Pousada da Lelinha e Pousada Zabelê.

Durante a fase de campo, também, foi feita uma observação in loco dos principais estabelecimentos alimentícios da cidade, para analisar a estrutura física, ambientes e cardápios.

Em função da inexistência de dados atuais sobre a demanda turística de SRN, utilizaram-se os únicos dados existentes sobre visitantes na região: o total de pessoas que visitaram o PNSC. Estes dados foram obtidos em pesquisa direta junto ao Instituto Chico Mendes de Biodiversidade - ICMBio, que possui registro diário do número de visitantes do PNSC.

De acordo com o ICMBio no período de janeiro a outubro de 2010 (período que antecedeu a pesquisa de campo) visitaram o PNSC 10.630 pessoas entre pagantes e não pagantes. A partir deste dado, calculou-se a média mensal, encontrando-se um valor de 1.063 visitantes/mês. Com este dado e empregando-se programa Raosoft (2010) com 8\% de margem de erro e $90 \%$ de nível de confiança calculou-se o número de questionáriosa serem aplicados nas pousadas e hotéis escolhidos.

Desta forma, a estratégia da coleta de dados foi através de levantamento, tipo survey de opinião, que conforme Brito (2008, p.4) "verifica a distribuição estatística das respostas a um questionário estruturado, aplicado a uma amostra da população" onde este tem como objetivo avaliar a percepção dos turistas quanto aos estabelecimentos de alimentação.

O instrumento principal deste levantamento foi um questionário estruturado com dezesseis perguntas abertas, fechadas e de múltipla escolha utilizando-se em algumas questões a escala de Likert 5 graus. Esses questionários foram distribuídos igualmente entre as pousadas e hotéis amostradas a fim de serem respondidos pelos turistas em cada estabelecimento hoteleiro. Dencker (1998,p. 183) define que "essa escala quantifica as atitudes dos indivíduos baseada em uma ordem de importância numérica qualificativa" de modo a obter do pesquisado sua percepção sobre as variáveis escolhidas para avaliar o grau de satisfação dos serviços de alimentação. No questionário também havia um espaço livre para comentários adicionais. 
Os questionários foramentregues na recepção sendo este setor o responsável pela distribuição entre os hóspedes. Foram objeto da pesquisa apenas hóspedes maiores de 18 anos com permanência mínima de um dia no município e que utilizaram os serviços dos estabelecimentos de alimentação pelo menos duas vezes.

\section{Turistas de São Raimundo Nonato - PI: perfil e grau de satisfação quanto aos serviços de alimentação}

Na primeira etapa da pesquisa, procurou-se identificar o perfil do turista que visita SRN. Entre os pesquisados 55\% são do sexo feminino e $45 \%$ são do sexo masculino. Em relação à idade, 38\% têm idade entre 18 a 25 anos, 17\% entre 41 a 50 anos, 16\% entre 26 a 30 anos, $13 \%$ entre 31 a 35 anos, $11 \%$ entre 51 a 60 anos e $5 \% 36$ a 40 anos. Percebe-se que a faixa etária está concentrada em um público jovem, entre 18 a 25 anos, provavelmente devido à pesquisa ter sido aplicada nos meses de novembro e dezembro, época que as instituições de ensino realizam viagens de encerramento de período letivo. Quanto ao grau de instrução, $53 \%$ dos turistas possuem nível superior incompleto, $21 \%$ pós-graduação completo/incompleto, $12 \%$ médio completo, $12 \%$ superior completo e $1 \%$ fundamental completo e ensino médio incompleto. É relevante ressaltar que o grau de instrução pode mais uma vez estar relacionado à aplicação da pesquisa nos meses de novembro e dezembro, por ser uma época conveniente para realização de viagens escolares, com finalidades de encerramento letivo ou até mesmo pesquisa concomitante com a disciplina que o aluno está cursando.

Oliveira Filho (2007) em sua dissertação de mestrado pesquisou a "Valoração Econômica da Atividade Ecoturística no Parque Nacional Serra da Capivara - Piauí" e fez um levantamento do perfil do turista que visita o PNSC. Segundo o autor, 46,34\% dos visitantes possuem ensino superior completo, 30,16\% nível superior incompleto, 11,09\% segundo grau completo, $8,87 \%$ segundo grau incompleto e $1,11 \%$ ensino fundamental completo. $\mathrm{O}$ autor complementa (p. 136):

Este contexto demonstrou que os praticantes do ecoturismo no PNSC são pessoas com conhecimento da realidade local e global, logo conscientes da necessidade da geração de benefícios para as comunidades receptoras e da proteção das áreas naturais e do conjunto arqueológico. 
Comparando-se os resultados encontrados com a pesquisa de Oliveira Filho (2007), constatase que os turistas são pessoas com nível de escolaridade elevado e que demonstram interesse na preservação das áreas ambientais, sem degradar o patrimônio natural e cultural.

Quanto ao estado civil $61 \%$ dos turistas são solteiros, $34 \%$ são casados, $4 \%$ separados e $1 \%$ viúvo.Quanto aos rendimentos dos turistas, 30\% manifestaram ter renda de 3 a 5 salários, ou seja, uma renda mensal quantificada entre $\mathrm{R} \$ 1.350$ e $\mathrm{R} \$ 2.250,00 ; 27 \%$ de 1 a 3 salários, $22 \%$ até um salário mínimo, $16 \%$ de 5 a 10 salários e 5\% acima de 10 salários mínimos.

Quanto à procedência dos turistas, 24,7\% declararam serem oriundos da cidade de Teresina PI, enquanto 19,6\% de Petrolina - PE, seguido de Oeiras - PI com 7,22\% e 6,19\% da cidade de Picos - PI. Estes dadosmostram que o estado do Piauí é o maior emissor do fluxo de turistas para SRN seguido de Petrolina-PE provavelmente devido à proximidade entre as cidades. Resultados semelhantes também foram encontrados em pesquisa realizada pelo projeto Caminhos do Sabor do Estado do Piauí com a aplicação de questionários com 28 turistas (ABRASEL, 2010). Segundo consta no citado documento, os turistas foram oriundos de Teresina (10,7\%), Oeiras (10,7\%) e Petrolina 7,14\%.

Segundo pesquisa realizada por Oliveira Filho (2007) sobre os turistas que escolhem SRN como destino turístico, constatou-se que entre os turistas de origem brasileira, $50,82 \%$ são piauienses, enquanto 14,52\% são procedentes de Pernambuco, seguido de São Paulo com 9,84\% e Bahia com 7,73\%. Estes dados expressam que o fluxo turístico nacional é predominantemente regional, sendo 79,39\% oriundos do Nordeste, com exceção do estado de São Paulo; $12,65 \%$ do Sudeste, 3,75\% do Centro-Oeste, 3,74\% do Sul e 0,46\% do Norte, com destaque para o estado do Piauí e cidades próximas ao PNSC, como Petrolina (PE), Juazeiro, Remanso e Casa Nova (BA), de um universo de 427 pesquisados. Quando somado os excursionistas (pessoas que visitam o PNSC em um dia e retornam a cidade de origem e que não foram inclusos nesta pesquisa), verifica-se que o turismo é realizado basicamente por pessoas que residem num raio de $500 \mathrm{~km}$ de distância de SRN. O fluxo turístico internacional ainda é pequeno, devido à falta de infraestrutura, principalmente pela obra inacabada do Aeroporto Internacional de SRN. Desta forma, comparando-se os dois resultados constata-se que o fluxo de turistas se confirma com as cidades do Piauí, destacando a capital Teresina e o 
estado de Pernambuco, com a cidade de Petrolina e ainda destaca-se o estado da Bahia, com a cidade de Juazeiro.

Entre os turistas que participaram da pesquisa, observa-se que 60\% dos turistas estavam visitando SRN pela primeira vez, seguido de $18 \%$ de turistas que já visitaram o município por cinco vezes ou mais, $12 \%$ por duas vezes e $5 \%$ por três ou quatro vezes. Percebe-se também que quanto ao tempo de permanência $51 \%$ dos turistas permaneceram na cidade durante dois dias, tempo suficiente para visitar os atrativos do município; $21 \%$ três dias, $20 \%$ cinco dias ou mais, $5 \%$ e $3 \%$, um dia e quatro dias respectivamente.

A análise da pesquisa verificou que $30 \%$ dos turistas justificaram as motivações da viagem como estudos, pesquisas e trabalhos científicos; $29 \%$ motivados por lazer; $20 \%$ como viagem a negócios e $17 \%$ eventos. Este último percentual se revela devido à cidade, no período de aplicação da pesquisa, estar sediando um evento no PNSC. Outros 3\% responderam aventura e $1 \%$ descanso. Destaca-se que a principal motivação dos turistas ao visitarem SRN é a busca por realização de pesquisas e estudos, visto que o PNSC é um patrimônio com sítios arqueológicos e "um local no qual homens deixaram algum vestígio de suas atividades: uma ferramenta de pedra, uma fogueira na qual assaram sua comida, uma pintura, uma sepultura, a simples marca de seus passos" (FUNDHAM, 2010).

Quanto à companhia da viagem, 74\% dos turistas estavam viajando com parentes, amigos e/ou colegas; $11 \%$ viajando sozinho, provavelmente uma viagem a negócios; 9\% na companhia de seu cônjuge ou namorado(a) e $6 \%$ viajando com os filhos.

Os meios de transporte utilizados pelos turistas distinguem-se em excursão, correspondendo a $44 \%$, automóvel próprio $31 \%$, ônibus intermunicipal $21 \%$ e $4 \%$ utilizaram o avião. SRN possui um aeroporto internacional em fase de construção, porém possui uma pista de pouso para aeronaves de pequeno porte que faz a entrega de malotes para algumas empresas de SRN. Outra forma de se chegar à SRN de avião é por dois portões de entrada, que pode ser via Teresina - PI ou via Petrolina - PE que possuem aeroporto.

Ao se cruzar os dados relacionados quanto à companhia da viagem com os dos meios de transporte utilizados constata-se que a maioria dos turistas visitava SRN em excursões, na companhia de parentes, amigos e/ou colegas e, provavelmente em viagem de estudo. Esta 
constatação também está relacionada ao baixo tempo de permanência na cidade uma vez que $51 \%$ dos turistas permaneceram na cidade durante somente dois dias.

A segunda etapa da pesquisa atém-se ao estudo direcionado ao grau de satisfação do turista quanto aos serviços de alimentação. Assim, o presente estudo procura identificar e analisar a percepção dos turistas quanto à comida local e sua aceitação.

Em se tratando de serviços, Zeithaml, Parassuraman e Berry (1990 apud Vidrik, 2006), mostram que a satisfação do cliente não se dá apenas em função do serviço final em si. No caso, não se daria apenas em função da qualidade dos pratos e bebidas servidos e outros tangíveis, mas sim, da qualidade de todo o processo envolvido desde quando o cliente entra no mesmo. Percebe-se que o serviço de alimentação é um somatório dos elementos tangíveis e intangíveis, que resultarão no elemento final, ou seja, a satisfação do cliente ou perda deste.

Deste modo, os turistas ao serem questionados sobre o local onde realizaram suas refeições, $63 \%$ responderam em hotel ou pousada, $29 \%$ em restaurantes e bares, $7 \%$ em lanchonetes e $2 \%$ em outros locais. É importante destacar que em todos os estabelecimentos hoteleiros a diária inclui, apenas, o café-da-manhã, reservando outras refeições à parte. Com este resultado, observa-se que a liderança nos serviços de alimentação para o atendimento do turista se concentra mais nos hotéis e pousadas, devido aos turistas já estarem instalados nos meios de hospedagem, como se constatou o turista passa em média dois dias na cidade, tempo suficiente para visitar os atrativos turísticos. Decerto, torna-se mais cômodo realizar as refeições no próprio hotel ou pousada mesmo sem a inclusão deste serviço na diária.

Em relação à frequência aos serviços de alimentação, 37\% dos turistas utilizaram os serviços de alimentação por 2 ou 3 vezes, 22\% 4 a 5 vezes, $21 \%$ não souberam responder, $13 \%$ mais de 7 vezes e $6 \%$ de 6 a 7 vezes. Mais uma vez, a quantidade de vezes que o turista utilizou os serviços de alimentação está diretamente ligada ao tempo de permanência na cidade.

No Gráfico 01, observam-se os atributos mais importantes na escolha de um bar, restaurante ou outro tipo de estabelecimento de serviço de alimentação, elencados pelos turistas. Desta forma, o atributo mais importante na visão dos turistas que visitavam SRN na aplicação da pesquisa, corresponde a $18 \%$ o quesito higiene e limpeza, bem como o bom atendimento e cordialidade dos atendentes. Portanto, cabe destacar o que Caetano (2006, p. 47) em sua dissertação de mestrado apontou sobre os atributos de escolha do alimento: 
Antes de optar pelo consumo de determinado produto alimentício, o consumidor lhe atribui valores com base em atributos intrínsecos, como suas características organolépticas, e atributos extrínsecos, como a representação simbólica desse alimento. Esses atributos embasam a percepção de qualidade que, por conseguinte, oferece subsídios para a percepção de valor do alimento. Essa última etapa no processo decisório se apresenta como sendo de alto nível de abstração, pois envolvem uma série de fatores de alta complexidade como os aspectos emocionais do ser humano, refletidos no julgamento individual de valores.

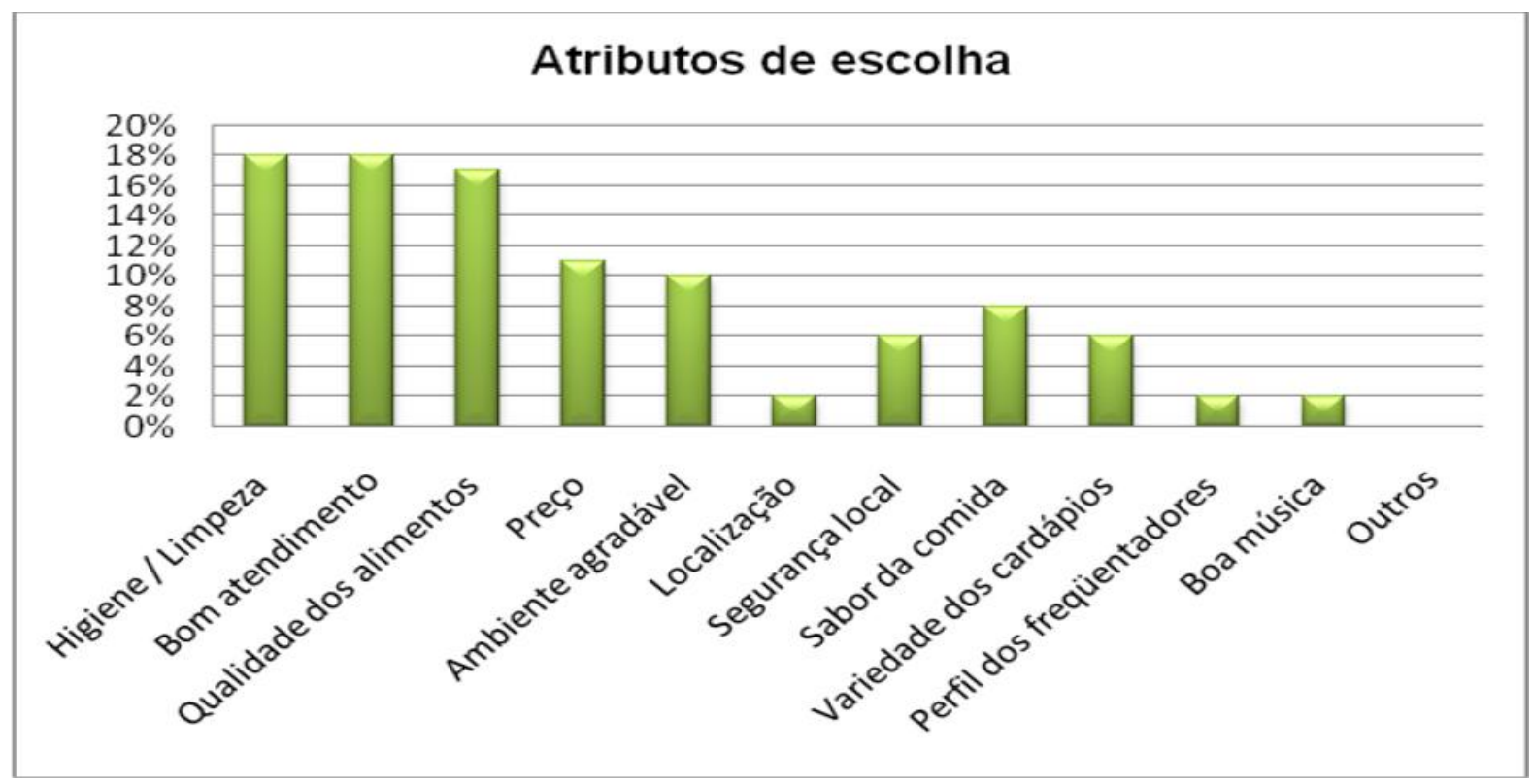

Fonte: Pesquisa direta, nov.- dez. / 2010.

Gráfico 01 - Distribuição percentual de turistas, em São Raimundo Nonato - PI, segundo os atributos de escolha do estabelecimento de alimentação.

Logo, a escolha do alimento está primeiramente associada à escolha do local da refeição, pois as características visuais são fatores determinantes para o cliente usufruir do cardápio do local. Verifica-se, também, a importância do bom atendimento, porque um erro pode gerar insatisfação no cliente e este nunca mais retornar ao estabelecimento.

Os dados revelam que o item qualidade do alimento obteve $17 \%$ entre os pesquisados indicando que o cliente está bem mais exigente e deseja comprar um produto que seja de qualidade. Em seguida, aparece o preço e o ambiente agradável, com $11 \%$ e $10 \%$ 
respectivamente, constata-se, então, que o preço não é o elemento fundamental na escolha do estabelecimento de alimentação.

Convêm ainda destacar, o sabor da comida com $8 \%$, segurança local e variedade dos cardápios, ambos com 6\%. Em menor grau de importância surge localização, perfil dos frequentadores e boa música correspondendo a $2 \%$ cada. Interessante ressaltar, que o sabor da comida, nesta pesquisa, não foi o elemento mais relevante entre os atributos pesquisados. Para os turistas, a higiene, limpeza e qualidade dos alimentos são os principais atributos para escolher um estabelecimento de alimentação.

Pereira (2001) aponta que o conceito de qualidade implica elementos de ordem psicológica como o prazer, o valor ideológico e simbólico e exigências objetivas como a qualidade nutricional, a qualidade sensorial e a segurança alimentar. Deste modo, a classificação geral quanto à qualidade dos estabelecimentos de alimentação de SRN (Gráfico 02) categoriza-se com $66 \%$ dentro do nível bom, seguida de $19 \%$ regular, $11 \%$ excelente, ruim e não sabe com $2 \%$, a categoria péssima não foi classificada. Ressalta-se que a qualidade percebida pelo consumidor se torna de difícil compreensão devido à complexidade do termo.

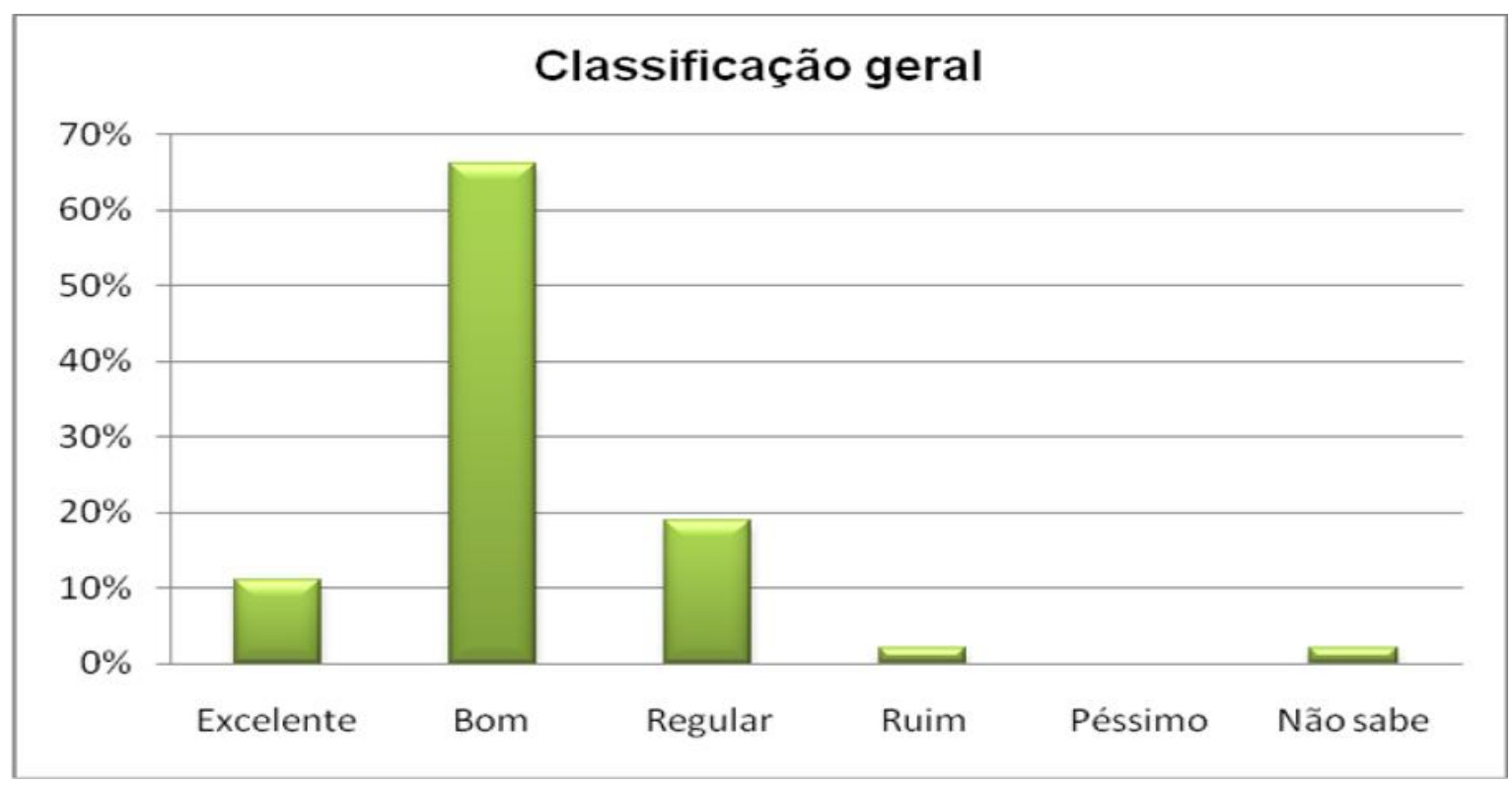

Fonte: Pesquisa direta, nov.- dez. / 2010.

Gráfico 02 - Distribuição percentual de turistas, em São Raimundo Nonato - PI, segundo a classificação geral dos serviços de alimentação 
A Tabela 02 retrata uma série de atributos percebidos no estabelecimento de alimentação e também na própria comida local, em que cada atributo corresponde a uma escala de satisfação, apresentando a porcentagem de cada uma, conforme o grau de satisfação do turista. Destaca-se que esta análise é o principal foco deste estudo. Segundo a Tabela 01, foram traçados os Gráficos 03 a 04, para uma melhor visualização da avaliação dos estabelecimentos de alimentação de SRN.

Tabela 02 - Distribuição percentual de turistas, em São Raimundo Nonato - PI, segundo a avaliação dos serviços de alimentação

\begin{tabular}{l|c|c|c|c|c|c}
\hline \multicolumn{1}{c|}{ Atributo } & TI & LS & PS & MS & ES & NS \\
\hline Agilidade/rapidez no atendimento & $5,2 \%$ & $32,2 \%$ & $15,6 \%$ & $31,3 \%$ & $11,5 \%$ & $4,2 \%$ \\
\hline Ambiente agradável & $10,5 \%$ & $16,8 \%$ & $12,6 \%$ & $33,7 \%$ & $23,2 \%$ & $3,2 \%$ \\
\hline Atendimento & $5,2 \%$ & $21,9 \%$ & $12,5 \%$ & $40,6 \%$ & $17,7 \%$ & $2,1 \%$ \\
\hline Cardápio variado & $3,1 \%$ & $20,4 \%$ & $23,5 \%$ & $28,6 \%$ & $20,4 \%$ & $4,1 \%$ \\
\hline Conforto & $9,5 \%$ & $22,1 \%$ & $16,8 \%$ & $28,4 \%$ & $20,0 \%$ & $3,2 \%$ \\
\hline Decoração & $10,2 \%$ & $24,5 \%$ & $18,4 \%$ & $27,6 \%$ & $14,3 \%$ & $5,1 \%$ \\
\hline Higiene & $7,6 \%$ & $25,0 \%$ & $17,4 \%$ & $33,7 \%$ & $13,0 \%$ & $3,3 \%$ \\
\hline Infraestrutura & $13,0 \%$ & $14,1 \%$ & $17,4 \%$ & $34,8 \%$ & $15,2 \%$ & $5,4 \%$ \\
\hline Preço & $4,3 \%$ & $17,4 \%$ & $22,8 \%$ & $38,0 \%$ & $13,1 \%$ & $3,3 \%$ \\
\hline Qualidade da comida & $2,1 \%$ & $22,1 \%$ & $11,6 \%$ & $41,0 \%$ & $18,9 \%$ & $4,2 \%$ \\
\hline Sabor da comida/tempero & $0,0 \%$ & $23,2 \%$ & $14,7 \%$ & $44,2 \%$ & $14,7 \%$ & $3,2 \%$ \\
\hline Boa apresentação dos pratos & $7,3 \%$ & $17,7 \%$ & $22,9 \%$ & $34,4 \%$ & $15,6 \%$ & $2,1 \%$ \\
\hline Porções bem servidas & $4,1 \%$ & $14,3 \%$ & $20,4 \%$ & $38,8 \%$ & $20,4 \%$ & $2,0 \%$ \\
\hline Orid
\end{tabular}

Onde: TI=Totalmente Insatisfeito / LS=Ligeiramente Satisfeito / PS=Pouco Satisfeito / MS=Muito Satisfeito / EX=Extremamente Satisfeito $/$ NS=Não Sabe

Fonte: Pesquisa direta, nov.- dez. / 2010.

Verifica-se que o atributo agilidade e rapidez (Gráfico 03) no atendimento correspondem a $32,20 \%$ como ligeiramente satisfeito, $31,25 \%$ muito satisfeito, $15,62 \%$ pouco satisfeito, $11,45 \%$ extremamente satisfeito, 5,20\% totalmente insatisfeito e 4,16\% não souberam responder. Nota-se que quanto à agilidade no atendimento é um quesito que deve melhorar, uma vez que o resultado encontrado foi ligeiramente satisfeito. Isto se deve muitas vezes à falta de capacitação dos colaboradores, bem como a um número insatisfatório destes. 
Quanto ao ambiente ser agradável, 33,68\% identificaram os estabelecimentos como muito satisfeitos, seguido de $23,15 \%$ extremamente satisfeito, $16,84 \%$ ligeiramente satisfeito, 10,52\% totalmente insatisfeito e 3,15\% não souberam responder (Gráfico 03).

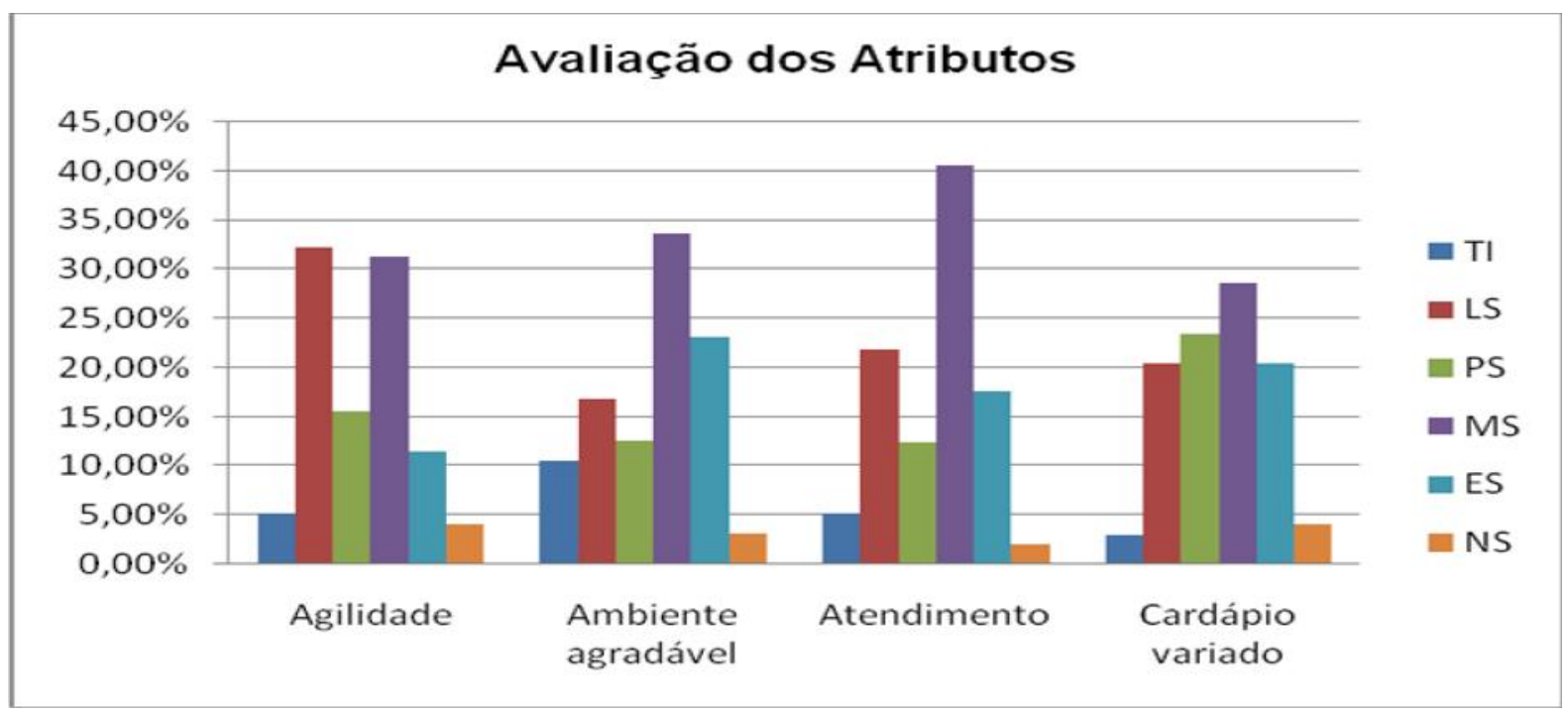

Fonte: Pesquisa direta, nov.- dez. / 2010.

Gráfico 03 - Distribuição percentual de turistas, em São Raimundo Nonato - PI, segundo a avaliação dos serviços de alimentação

O atendimento surge com 40,62\% como muito satisfeito, 21,87\% como ligeiramente satisfeito, $17,70 \%$ extremamente satisfeito, $12,50 \%$ pouco satisfeito, 5,20\% totalmente insatisfeito e 2,08\% não sabe (Gráfico 03). Comparando-se a agilidade com o atendimento, tem-se que a primeira classificou-se como ligeiramente satisfeito, ou seja, o garçom ou os demais atendentes podem proporcionar um atendimento cortês, porém podem não ser ágeis.

Quanto ao item "cardápio variado" $28,57 \%$ opinaram como muito satisfeito, $23,46 \%$ pouco satisfeito, 20,40\% ligeiramente satisfeito e extremamente satisfeito, 4,08\% não sabe e 3,06\% totalmente insatisfeito (Gráfico 03). Destaca-se a importância do cardápio em um restaurante, em que Pinto (2009, p. 40), considera que "a função primordial do cardápio é informar que iguarias o estabelecimento tem a disposição da clientela. Os pratos que compõem o menu devem ser variados, equilibrados e adequados a cada tipo de estabelecimento". Em virtude 
disso, destaca-se que o cardápio é o cartão de visitas de um restaurante, bem como um instrumento de vendas.

O conforto é uma questão que depende da subjetividade humana, cada um com seus paradigmas e cultura, tem seu modo de ver o conforto, mas sabe-se que a palavra está associada a bem estar. Assim, quanto a este item $28,42 \%$ dos turistas se sentiram muito satisfeitos, enquanto $22,10 \%$ se sentiram ligeiramente satisfeitos, seguido de $20 \%$ extremamente satisfeito, $16,84 \%$ pouco satisfeitos, $9,47 \%$ totalmente insatisfeito e $3,15 \%$ não souberam (Gráfico 04).

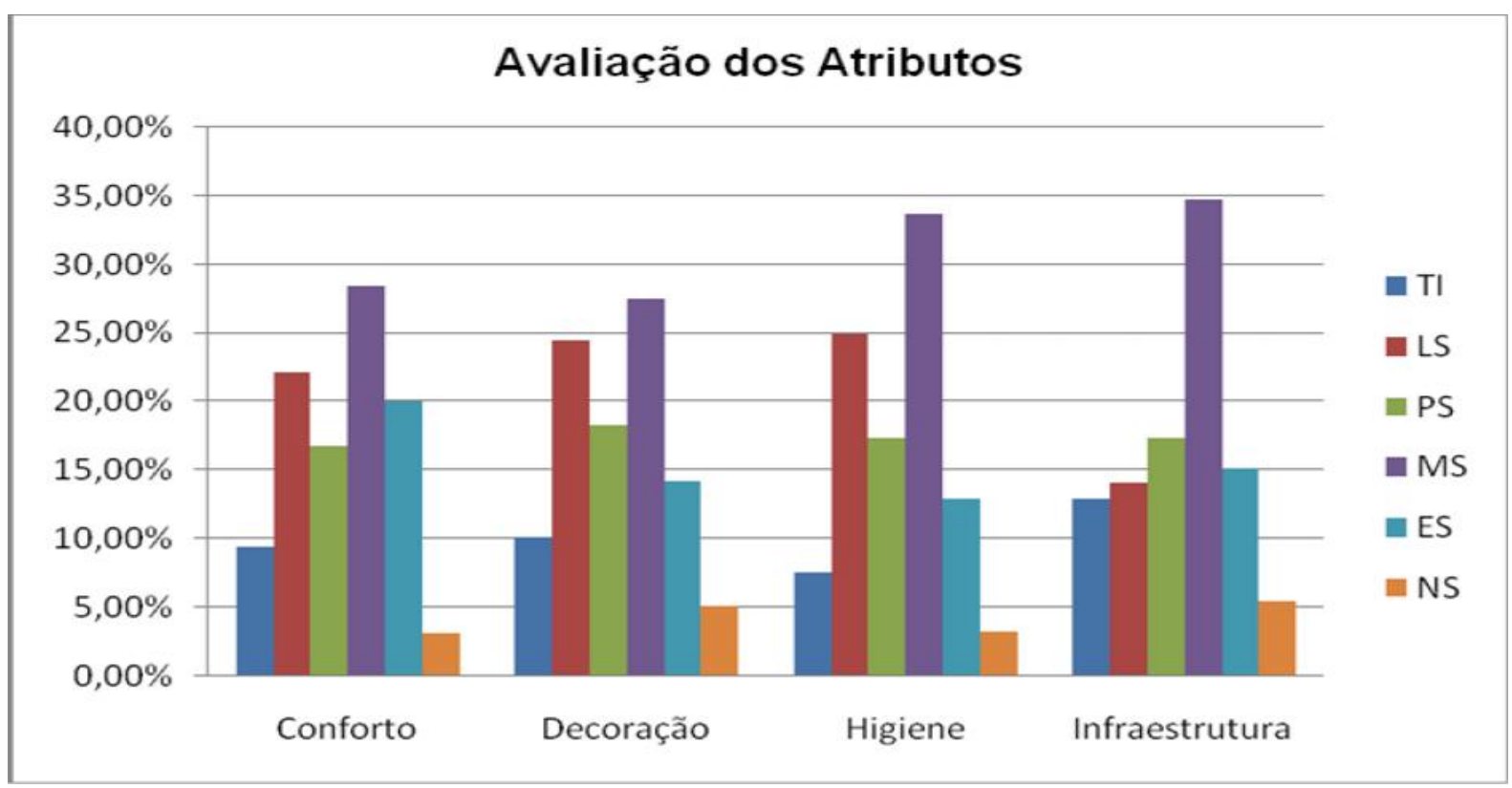

Fonte: Pesquisa direta, nov.- dez. / 2010.

Gráfico 04 - Distribuição percentual de turistas, em São Raimundo Nonato - PI, segundo a avaliação dos serviços de alimentação

Librizzi (2007) afirma que os clientes estão valorizando cada vez mais a ambientação, a arquitetura e a decoração dos restaurantes, uma vez que têm percebido que frequentar bons lugares agrega status cultural e social aos mesmos. Desta forma, a decoração dos estabelecimentos de SRN obteve-se uma porcentagem de 27,55\% muito satisfeito, $24,48 \%$ ligeiramente satisfeito, $18,36 \%$ pouco satisfeito, $14,28 \%$ pouco satisfeito, $10,20 \%$ totalmente insatisfeito e 5,10\% não souberam (Gráfico 04). Desta forma, quanto à infraestrutura dos 
estabelecimentos corresponde a $34,78 \%$ muito satisfeito, $17,39 \%$ pouco satisfeito, $15,21 \%$ extremamente satisfeito, $14,13 \%$ ligeiramente satisfeito, $13 \%$ totalmente insatisfeito e 5,43\% não sabe (Gráfico 04). Campos (2008) complementa que o atrativo principal de um restaurante pode ser a decoração, muitas vezes assinada por um arquiteto famoso e afirma que quem escolhe um restaurante, sabe o que procura, e geralmente volta por conta dos detalhes, da sensação que o lugar proporciona.

Quanto à higiene, 33,69\% dos turistas classificaram como muito satisfeito, 25\% ligeiramente satisfeito, $17,39 \%$ pouco satisfeitos, $13 \%$ extremamente satisfeito, $7,60 \%$ totalmente insatisfeitos e 3,26\% não sabe (Gráfico 04). Estes dados mostram que os restaurantes locais oferecem um serviço com condições higiênicas satisfatórias. Ressalta-se que a higiene do local foi apontada por $18 \%$ dos turistas pesquisados como o atributo mais importante para a escolha de um estabelecimento de alimentação.

A higiene envolve aspectos como procedimentos e higiene no trato com os alimentos, na limpeza de utensílios manipulados, na limpeza do ambiente e nas condições do manipulador de alimentos. Acrescenta-se que de acordo com estudos estatísticos da Organização Mundial de Saúde (OMS), mais de 60\% dos casos de doenças de origem alimentar decorrem de técnicas inadequadas de processamento estando relacionados à deficiência de higiene ambiental e de utensílios, maus hábitos dos manipuladores, manutenção ou reaquecimento dos alimentos em temperaturas inadequadas, mau acondicionamento, contaminação cruzada, entre outros (HOBBS e ROBERTS, 1998). Acentua-se que este resultado pode ter sido escolhido pelo turista mais pelo caráter visual, tanto do alimento, como do atendente, do salão e dos sanitários, pois na realidade este não sabe exatamente como o seu alimento estava sendo processado.

O critério preço, segundo os turistas, está dentro da realidade, uma vez que $38 \%$ responderam estar muito satisfeito, $22,82 \%$ pouco satisfeito, $17,39 \%$ ligeiramente satisfeitos, $13,13 \%$ extremamente satisfeitos, enquanto $4,34 \%$ totalmente insatisfeitos e 3,26\% não souberam responder (Gráfico 05). 


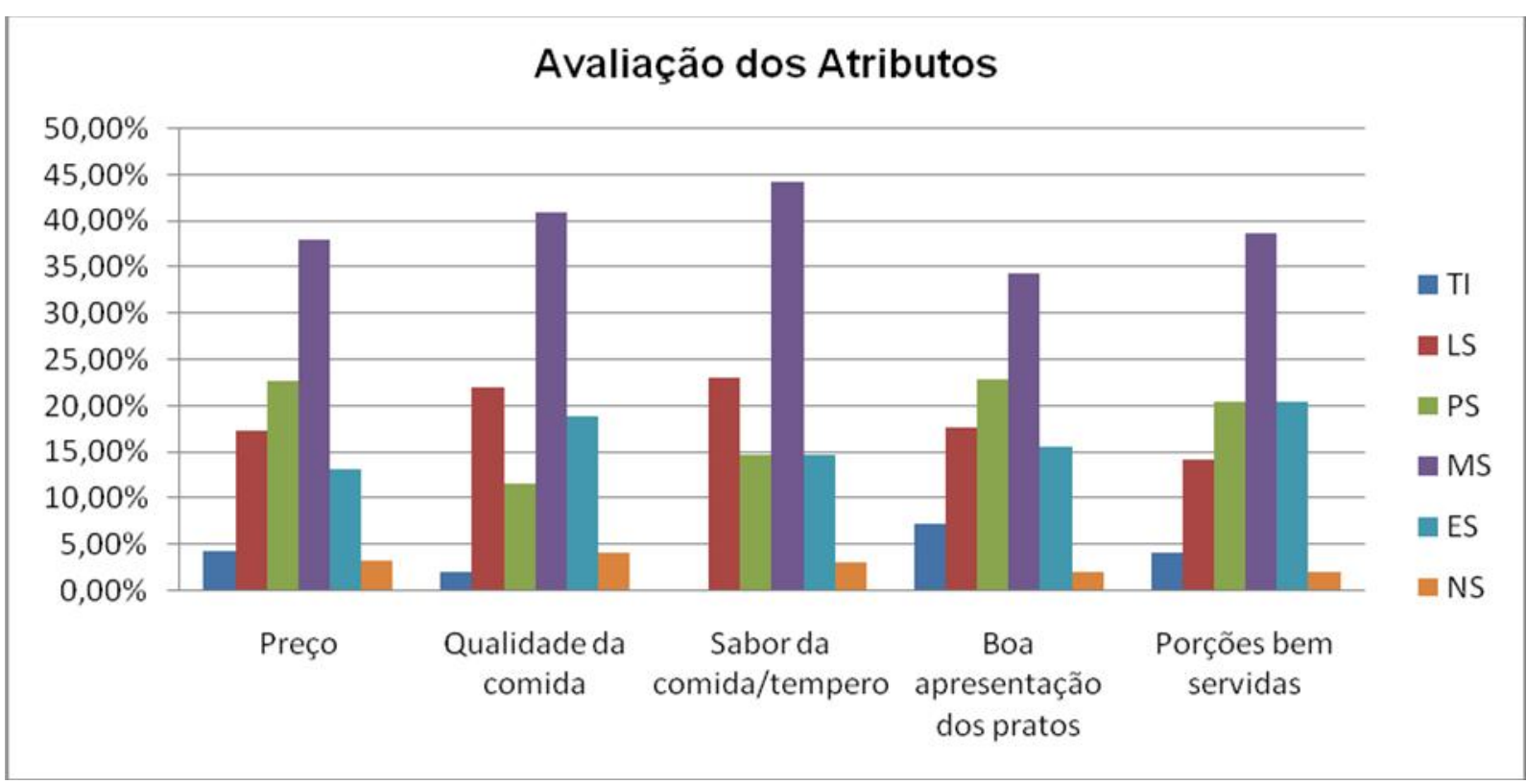

Fonte: Pesquisa direta, nov.- dez. / 2010.

Gráfico 05 - Distribuição percentual de turistas, em São Raimundo Nonato - PI, segundo a avaliação dos serviços de alimentação

Em relação à qualidade da comida $41 \%$ responderam estar muito satisfeito, $22,10 \%$ ligeiramente satisfeito, $18,94 \%$ extremamente satisfeito, $11,57 \%$ pouco satisfeito, $4,21 \%$ não sabe e $2,10 \%$ totalmente insatisfeito. Quanto ao sabor da comida 44,21\% classificaram como muito satisfeito, 23,15\% ligeiramente satisfeito, $14,73 \%$ como extremamente satisfeito e pouco satisfeito, 3,15\% não souberam (Gráfico 05). Estes resultados demonstram uma satisfação do turista quanto à qualidade da comida oferecida e do seu sabor confirmando o prestigio do município na elaboração dos seus pratos. Este fato pode está relacionado à participação dos estabelecimentos de restauração no festival de gastronomia que ocorre anualmente em SRN. Durante este evento há um concurso com premiação para o melhor prato elaborado estimulando, dessa forma, a melhoria dos estabelecimentos de alimentação existentes na cidade.

Assim, os restaurantes de SRN preocupam-se constantemente com o visual dos pratos elaborados e com a sua apresentação, o que se pode constatar através do grau de satisfação dos clientes. Do total de turista pesquisado, 34,37\% responderam estar muito satisfeito, $22,91 \%$ pouco satisfeito, $17,70 \%$ ligeiramente satisfeito, $15,62 \%$ extremamente satisfeito, 7,29\% totalmente insatisfeito e 2,08\% não sabe (Gráfico 05). Em relação às porções servidas, 
$38,77 \%$ ficaram muito satisfeito, $20,40 \%$ pouco satisfeito e extremamente satisfeito, $14,28 \%$ ligeiramente satisfeito, 4,08\% totalmente insatisfeito e 2,04\% não sabe (Gráfico 05).

\section{Considerações Finais}

Diante dos resultados alcançados no estudo descritivo e transversal, pôde-se constatar que os restaurantes que compõem a oferta turística de São Raimundo Nonato apresentaram um nível satisfatório na qualidade dos serviços, conforme a avaliação dos turistas, exemplo disto foi o item atendimento realizado, sendo bem destacado e aceito pelos turistas, bem como foi ressaltado pelos mesmos a hospitalidade nata do povo da cidade.

Quanto aos objetivos específicos do estudo proposto encontrou-se um resultado positivo, uma vez que, identificou-se que os turistas realizam suas refeições, no próprio hotel ou pousada nos quais estão hospedado, por 2 a 3 vezes, em média. Para a escolha de um estabelecimento de alimentação a maioria dos turistas apontou os atributos: higiene e limpeza, bom atendimento e qualidade dos alimentos. E que segundo a classificação geral dos serviços de alimentação estes estabelecimentos são de bom nível.

Estimaram-se, principalmente os serviços de alimentação, quanto às suas características principais: sabor, capacidade de despertar o apetite, apresentação do prato, higiene e preço e os índices que alcançaram melhores dimensões foram: atendimento, qualidade da comida e o sabor da comida. Também se identificaram os índices com razoável nível de satisfação, sendo apontados: a agilidade, a decoração e a higiene.

Deste modo, os restaurantes foram considerados aceitáveis, confiáveis e que atendem as necessidades dos clientes. Porém, este resultado poderia se apresentar de forma diferente, caso esses mesmos turistas utilizassem os restaurantes, lanchonetes e pizzarias da cidade, já que a pesquisa identificou que o local mais utilizado de refeição dos turistas foram os hotéis e pousadas em que estes estavam hospedados. Neste caso, compete ao condutor do grupo valorizar também a culinária local e os restaurantes da cidade, apresentando aos turistas outras opções de alimentação na cidade de SRN, que não se resuma somente aos hotéis e pousadas.

Foi observado na análise dos dados, que os turistas se apresentaram insatisfeitos quanto à agilidade dos garçons, portanto, além da capacitação dos colaboradores, é preciso, conforme 
observação de campo, que os empregadores ofereçam condições favoráveis de trabalho, pois há pizzarrias que apenas um garçom atende a dez mesas ao mesmo tempo, tornando a espera cansativa e enfadonha.

Observou-se que os cardápios dos restaurantes de SRN são repetitivos e fora dos padrões de boa apresentação. Sabe-se que o cardápio é o instrumento de vendas de um restaurante e é o seu cartão de visitas, assim, ressalta-se a importância que os serviços de alimentação precisam desenvolver para melhoria da apresentação do seu cardápio.

A decoração é muitas vezes um item que seleciona as pessoas que irão entrar no restaurante, portanto, a decoração tem que ser pensada para agradar ao público que lhe interessa, mostrando quais são os valores da empresa e enfatizando a sua marca e imagem. Além do espaço de atendimento aos clientes, é preciso estudar as atividades que os colaboradores exercem, assim, deve-se pensar que áreas devem estar próximas, como será a circulação pelo recinto, a iluminação, limpeza, ventilação, manutenção, enfim, o fluxograma de todo o estabelecimento e neste ponto os serviços de alimentação de SRN apresenta aspectos desfavoráveis e de desinteresse.

Observa-se que faltam mais ações voltadas para o entretenimento em SRN uma vez que 17\% dos entrevistados vieram à cidade motivados pela ocorrência de eventos e $2 \%$ citaram o oferecimento de boa música como critério para escolha do estabelecimento de alimentação. Assim, seria interessante que a cidade oferecesse aos turistas, especialmente à noite, opções de lazer como shows, música de qualidade etc. Os restaurantes e pizzarias poderiam,por exemplo,criar espaços destinados tambémà diversão das crianças, uma vez que há certa carência neste aspecto.

Conclui-se, portanto, que as informações presentes neste trabalho podem servir de base para que os gestores de alimentação obtenham a excelência na prestação de serviços de alimentação, através conhecimento sobre a opinião dos turistas de SRN e do reconhecimento de pontos considerados fracos por esse público, para que possam buscar a melhoria contínua e atender adequadamente a demanda turística e população local. 


\section{Referências}

ARAÚJO, J. L. L. (Coord.). Atlas escolar do Piauí: Geo-histórico e Cultural. João Pessoa, PB: Editora Grafset, 2006.

BARROS, C. A Surpreendente Comida do Piauí. Revista PiauíTUR, Teresina, 01 jun. 2009. Caderno 01, Folha Gastronomia, p. 20.

BRAGA, D. C. Planejamento Turístico: Teoria e Prática. Rio de Janeiro: Elsevier, 2007.

BRASIL. MTur. Plano Nacional de Turismo 2007 - 2010. Brasília, DF: MTur, 2007.

ABRASEL. Caminhos do Sabor: A União Faz o Destino, Desenvolvimento de Destinos Turísticos através da Gastronomia - Fortaleza-CE, 2008.

. Caminhos do Sabor: A União Faz o Destino, Desenvolvimento de Destinos Turísticos através da Gastronomia - São Raimundo Nonato-PI, 2010.

CAETANO, M. Estudo das Práticas Alimentares dos Turistas: Uma Contribuição Metodológica para o Planejamento Turístico e o Fortalecimento do Agronegócios. 91 f. Dissertação (Mestrado em Agronegócios). Campo GRANDE / MS - Brasília / DF - Goiânia / GO setembro, 2006.

CAMPOS, C. Restaurantes Seduzem Clientes pela Comida e pela Decoração. Disponível em:<http://estilo.uol.com.br/ultnot/2008/02/20/ult3617u3070.jhtm>. Acesso em $27 \mathrm{de} \mathrm{dez.} \mathrm{de} 2010$.

CARVAlHO, S. M. S. Possibilidades e Limitações do Desenvolvimento Sustentável do Turismo no Município de Cajueiro da Praia (PI). 159 fls. Dissertação (Mestrado em Desenvolvimento e Meio Ambiente). PRODEMA/UFPI/TROPEN, Teresina: UFPI, 2010.

CASTELLI, G. Gestão Hoteleira. São Paulo: Saraiva, 2006.

DENCKER, A. de F. M. Métodos e Técnicas de Pesquisa em Turismo. São Paulo, SP: Futura, 1998.

OLIVEIRA FILHO, R. C. de. Valoração Econômica da Atividade Ecoturística no Parque Nacional Serra Da Capivara - Piauí. Dissertação (Mestrado) Programa de Pós-Graduação em Desenvolvimento e Meio Ambiente. Universidade Federal do Piauí, Teresina, UFPI, 2007. 183 f.

FUNDHAM. Sítios Arqueológicos. Disponível em: <http://www.fumdham.org.br/mapas.html>. Acesso em 21 de dez. de 2010.

HOBBS, B. C.; ROBERTS, D. Toxinfecções e controle higiênico-sanitário de alimentos. São Paulo: Livraria Varela, 1998.

IBGE. Economia do Turismo: Uma Perspectiva Macroeconômica 2003-2007. Rio de Janeiro, 2007.

LIBRIZZI, É. Bons ventos em 2007. Disponível em: 〈www.abrasel.com.br〉. Acesso em: 27 de dez. 2010.

OMT. Introdução ao Turismo. Direção e Redação: Amparo Sancho. Tradução Gleice Regina Guerra. São Paulo: Roca, 2001.

PEREIRA, L. K. O processo de valorização de produtos alimentícios através de denominações de origem e qualidade: uma abordagem de gestão do conhecimento. Dissertação (Mestrado) Programa de Pós-Graduação em Engenharia da Produção. Universidade Federal de Santa Catarina, Florianópolis, UFSC, 2001. $153 \mathrm{f}$.

PINTO, D. R. G. Sistemas e Técnicas de Sala-bar. Fortaleza: UAB/IFCE, 2009.

Portal Prefeitura Municipal SRN. Onde Comer. Disponível em: <http://www.saoraimundononato.pi.gov.br/fixas/onde_comer.html>. Acesso em 26 de dez. de 2011. 
Portal SRN. Pizzaria Paulinho ganha $2^{o}$ Mostra Gastronômica de SRN. Disponível em: <http://www.saoraimundo.com/noticias/headline.php?n_id=8009>. Acesso em 04 de jan. de 2011.

RAOSOFT. Simple size calculator. Disponível em: <http://www.raosoft.com/samplessize.htm>. Acesso em 10 de novembro de 2010.

VIDRIK, K. N. Indicadores de Qualidade do Restaurante Universitário da Universidade do Sagrado Coração - Bauru, SP: Um Estudo De Caso. Dissertação (Mestrado) Programa de Pós-Graduação em Planejamento e Gestão Estratégica em Hospitalidade. Universidade Anhembi Morumbi, São Paulo, 2006. 132 fls.

\section{Recebido em: 04/05/2011}

Aprovado em: 29/11/2011 (1 ${ }^{\text {a }}$ versão) $29 / 05 / 2012$ (2 $2^{\text {a }}$ versão) 